\title{
Assessing the Usability of a Tumor Dashboard for Multidisciplinary Care Teams for First Time Users; First Exploration of a Comparative Participatory Cognitive Walkthrough to Show Mismatches in Cognitive Models
}

\author{
Emmanuelle ter BEEK ${ }^{\mathrm{a}, 1}$, Milan KOS ${ }^{\mathrm{b}}$, Mirte STREPPEL ${ }^{\mathrm{b}}$, Linda DUSSELJEE- \\ PEUTE $^{\mathrm{a}}$, and Martijn van OIJEN ${ }^{\mathrm{b}}$ \\ ${ }^{a}$ Department Medical Informatics, University of Amsterdam, Amsterdam University \\ Medical Center, Amsterdam, the Netherlands \\ ${ }^{b}$ Department Oncology, Amsterdam University Medical Center, Amsterdam, The \\ Netherlands
}

\begin{abstract}
Due to the COVID-19 pandemic, multidisciplinary team (MDT) meetings have to switch from physical to digital meetings. However, the technology they currently use to facilitate these meetings can sometimes be lacking, therefore many software companies have developed new software to ease our new digital workspace. In this study, we propose a new method, a comparative participatory cognitive walkthrough, which can show mismatches in cognitive models. To test our method, we tested the compatibility of EPIC EMR (EPIC Care) and the NAVIFY Tumor Board for preparing MDT meetings. The identified mismatches are categorized in the HOT-fit model by Yusof et al, a common way to evaluate if a healthcare information system fits with the healthcare professionals and the organization. In total, 16 mismatches were identified. These mismatches were discussed in a feedback session with an implementation manager of the NAVIFY Tumor Board. The proposed method seems to be a fast and cheap method to gain useful insights in how well new software matches with the software currently in use, by comparing the cognitive models in place when performing tasks involved with specific scenarios. The identified aspects can be of use for the development and adaptation of the new software, as well as provide guidelines on which aspects to focus on when training healthcare professionals to use the new software to have a smooth transition of software.
\end{abstract}

Keywords. Usability evaluation, Comparative Participatory cognitive walkthrough, UX research, MDT meeting, Tumor Board

\section{Introduction}

Compared to new technologies, the healthcare systems and technologies used in hospitals

${ }^{1}$ Corresponding author: Emmanuelle ter Beek, Department of Medical Informatics, University of Amsterdam, Amsterdam, the Netherlands. Email: e.c.terbeek@amsterdamumc.nl. 
in the Netherlands are often dated. Therefore, many healthcare professionals want to switch to recently developed technologies (systems, apps, platforms) proven to be more efficient and beneficial for their work and to their organization. Even though these technologies score high on efficiency, often the usability and user-friendliness are not taken into account. For the implementation and acceptance of technologies, the importance of user experience is increasing.

Due to the COVID-19 pandemic, the use of online technologies that facilitate working remotely has become popular. For creating personal treatment plans for patients in cancer care, multiple, relevant healthcare providers from different fields of expertise (e.g. oncologists, radiologists, pathologists) are involved in the care process [2]. They discuss the diagnostic, treatment and after-care process in so-called multidisciplinary team meetings (MDT meetings) [3]. Usually, due to the complexity of cancer care and the continuously improving and expanding clinical expertise of healthcare professionals, an MDT meeting will be held with professionals within each hospital if possible, and regionally or nationally when more expertise is required [4]. In general MDT meetings would be a physical meeting. However, due to the COVID-19 pandemic, MDT meetings have been forced to switch from physical to digital meetings [5].

Some of the new technologies created are for facilitating online MDT meetings, such as Roche's Diagnostics' NAVIFY. For new technologies, especially ones created for a different country (US) in a different language and following different guidelines, it is difficult to find out its compatibility and usability when matching the software to the needs and practices of Dutch healthcare professionals. A usability evaluation method that supports research on all important aspects (usability, user satisfaction, learnability and structure) is cognitive walkthrough $(\mathrm{CW})$. It is designed to see whether or not a new user can easily carry out tasks using a specific system [6]. With this method, an expert inspects the user interface of the software in a very structured manner from the perspective of the user, using specific scenarios, consisting of tasks and subtasks. Each subtask is then evaluated on different cognitive aspects such as recognition, awareness and mental feedback.

There are many different adaptations of the CW method, one of which is the participatory $\mathrm{CW}$. With a regular participatory $\mathrm{CW}$, end users and experts would collaboratively run through the application in a highly structured manner and evaluate each task and subtasks on several cognitive aspects. However, this method will not give you information about how usable and understandable a new software system is when compared to the software end-users are currently using. Therefore, in this study we have adapted the performance of the participatory $\mathrm{CW}$ by applying it in a comparative setting in order to gain sight into the mismatches in the user's cognitive model (their way of thinking) when they have been using a certain software and are trying out a new software based on scenarios. Furthermore, we will use the HOT-fit model, which is a common way of evaluating whether or not a health information system fits with the healthcare professionals and the organization, to categorize the identified mismatches and show their influence [7].

In this study, we propose a proof of concept for an adaption of the participatory cognitive walkthrough method. Our goal is to gain insights into the potential usability issues of the new software for new users that are used to the cognitive model of executing certain tasks in their current system. By mapping the current tasks for preparing a MDT meeting in a current setting with EPIC software to preparing an MDT meeting using the NAVIFY Tumor Board, we gain insights into the mismatches in usability for the transition from the current software to new software. Furthermore, we can identify what 
type of issues and problems are encountered. With this information, we can show which challenges healthcare professionals experience when transitioning from using EPIC in MDT meetings would encounter when switching to using the NAVIFY Tumor Board.

With this knowledge, recommendations regarding additional functionalities and terminology can be formulated to fit the software to the healthcare process as it currently is. Furthermore, for training purposes, bottlenecks and other aspects that may require more attention can be identified.

\section{Software}

To test the participatory cognitive walkthrough and identify the mismatches in cognitive models, a case was used in which EPIC was the 'old' software, and Roche Diagnostics' NAVIFY the 'new' software.

EPIC is one of the largest providers of health information technology to access, organize, store and share electronic medical records (EMRs) [8]. The EPIC EMR (EPIC Care) can keep community providers and caregivers up to date with an integrated portal that shows them their patients, lets them submit referrals, order laboratory tests and imaging, and more [9]. The Amsterdam University Medical Center (Amsterdam UMC) has used the EPIC EMR since 2013 [10]. Currently, EPIC Care, as being used in the Amsterdam UMC, does not have a dedicated module for creating and preparing MDT meetings.

The NAVIFY Tumor Board is a cloud-based workflow product that securely integrates and displays relevant aggregated data into a single holistic patient dashboard [11]. The NAVIFY Tumor Board is created to facilitate the preparation, discussion and decision phase of a MDT meeting for cancer care and can be integrated with the EMR [11]. Furthermore, based on the data entered, it can show for which recruiting studies a patient could apply, search for relevant study publications, and provide an interactive overview of the guidelines applicable to each specific patient.

Several studies on the usability of the NAVIFY Tumor Board have already been conducted [12-16]. Three of these studies were observational studies, one study was a prospective cohort, and one was a simulation-based study with structured scenarios, respectively. The results from these studies show positive outcomes in regards to efficiency and reduction of preparation time. No expert evaluation on the usability of the NAVIFY Tumor Board has been performed yet.

\section{Proposed method}

\subsection{Comparative participatory cognitive walkthrough approach}

In order to match the new software to the currently used one, first, scenarios need to be created. These scenarios will then be executed in two different sessions. The comparative participatory walkthrough consists of six phases. In phase one, a structured document and scenarios need to be prepared. In the second phase (the first walkthrough session), end users execute the scenarios using their current software programme (EPIC Care). Whilst executing the created scenarios, all tasks (assignment) and subtasks (steps with which the assignment can be completed) are recorded by the expert. For each subtask, 
the expert also records encountered problems and inefficiencies. Phase three consists of specifying and structuring the identified main tasks in a new document. In the fourth phase (the second walkthrough session), the identified tasks from the first session are executed using the new software (NAVIFY Tumor Board). Whilst executing the identified tasks, the end user and expert compare the execution processes in the two different softwares. Difficulties, dissimilarities and dysfunctionalities are recorded and assigned a severity rate (as described by Nielsen) by the oncologist [17]. By executing the identified tasks of the current work process, an insight is gained into how well the new software supports the current task system. The fifth phase consists of mapping tasks and categorizing difficulties, dissimilarities and dysfunctionalities. In the last phase, the identified aspects are discussed with an employee from Roche Information Solutions in a feedback session, to gain further insights into these aspects and what can be done to avert or lessen the impact of the mismatches.

For this study, the recorded aspects are categorized using the HOT-fit model in which aspects are accommodated in the specific aspects within the 'human', 'organization', or 'technology' domain (see figure 1 [7]. The first author coded the identified issues and discussed the analysis with the fourth author.

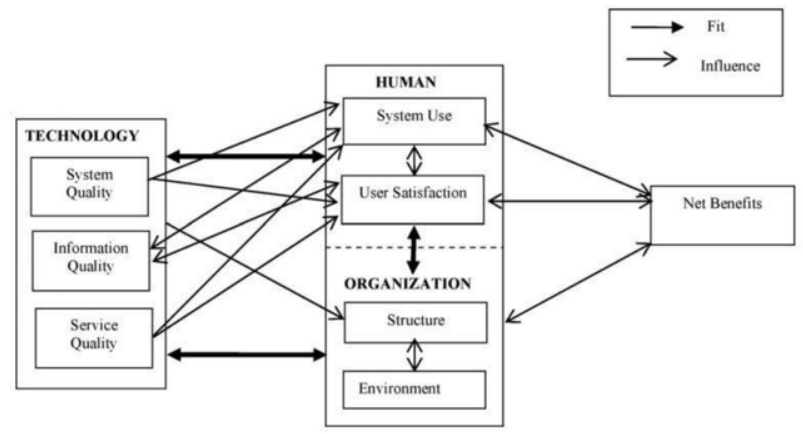

Figure 1. Human-organization-technology-fit (HOT-fit) framework as proposed by Yusof et al.

\subsection{Participants}

In line with the participatory $\mathrm{CW}$ method, two participants performed the analysis. The first participant is the 3rd author, a 34-year old oncologist working at the Amsterdam UMC in the Netherlands with approximately one year experience in using Epic Care and no experience using the NAVIFY Tumor Board. The second participant is the 1st author, a 22-year old master's student in Medical Informatics from the University of Amsterdam, trained in performing usability tests (specifically $\mathrm{CWs}$ ), with little to no experience using EPIC Care and the NAVIFY Tumor Board.

\subsection{Scenarios}

Two different scenarios were used for the comparative participatory walkthrough. These scenarios were conceptualized by the 5 th author, defined by the 1 st author, and revised by the 5 th author.

Scenario 1: 'Patient A has had surgery for a colon carcinoma. The treating physician is wondering whether or not the patient would benefit from starting adjuvant systemic therapy (treatment to prevent the recurring of a carcinoma). Patient $\mathrm{A}$ is diagnosed as a 
stage 2, high risk patient, therefore adjuvant therapy should be discussed in an MDT meeting.'

Scenario 2: 'Patient B has stage 4 colon carcinoma with synchronous metastases. Metastases are not well resectable, even after induction therapy. Therefore, it was decided to start palliative systemic therapy. The available information on different types of palliative therapy may not be up to date. Patient B could therefore be discussed in a national expert panel, in which new studies are also discussed.'

\section{Results}

We encountered nine aspects categorized in Technology: information quality. Most aspects were dysfunctionalities $(n=10)$, some were dissimilarities in the execution of tasks $(n=3)$ or technical difficulties $(n=3)$. In Table 1 , the identified aspects are presented with their HOT-fit category. The implementation manager of the NAVIFY Oncology Decision Support portfolio from Roche Information Solutions, was asked to review and reflect upon these aspects. The status of the aspects (whether or not NAVIFY was aware/unaware of the aspect and if the system is able/unable to support this aspect) and the employee's' comments are included in the column 'Status' and 'Review NAVIFY' in Table 1.

There were three potential usability issues of which NAVIFY was unaware (unaware/unable) of and three aspects that involved execution problems due to dissimilarities (aware/able). Lastly, the two aspects 'Indication for revision' and 'Treating physician' are aspects that have to be recorded in the EMR, due to legislations and should not be recorded in the NAVIFY Tumor Board according to the implementation manager even though the oncologist expected to be able to record this in the NAVIFY Tumor Board.

Table 1. Results from the comparative participatory $\mathrm{CW}$ and the review from NAVIFY

\begin{tabular}{|c|c|c|c|c|}
\hline Aspect & HOT-fit category & Status & Review NAVIFY & Severity \\
\hline $\begin{array}{l}\text { Chairman } \\
\text { MDT } \\
\text { meeting }\end{array}$ & $\begin{array}{l}\text { Technology: } \\
\text { information quality } \\
\text { - completeness }\end{array}$ & $\begin{array}{l}\text { Aware } \\
\text { Unable }\end{array}$ & $\begin{array}{l}\text { Aware that one person has to be } \\
\text { appointed chairman, but this is not } \\
\text { possible in the software. }\end{array}$ & 4 \\
\hline Referrer & $\begin{array}{l}\text { Technology: } \\
\text { information quality } \\
\text { - accuracy }\end{array}$ & $\begin{array}{l}\text { Unaware } \\
\text { Unable }\end{array}$ & $\begin{array}{l}\text { Unaware that it is important to record } \\
\text { the referrer of the patient. Currently, } \\
\text { only the physician that added the } \\
\text { patient to the MDT meeting is visible. }\end{array}$ & 3 \\
\hline Anamnesis & $\begin{array}{l}\text { Technology: } \\
\text { information quality } \\
\text { - completeness }\end{array}$ & $\begin{array}{l}\text { Aware } \\
\text { Unable }\end{array}$ & $\begin{array}{l}\text { Is added in the august/september } \\
\text { update. }\end{array}$ & 4 \\
\hline $\begin{array}{l}\text { Family } \\
\text { history }\end{array}$ & $\begin{array}{l}\text { Technology: } \\
\text { information quality } \\
\text { - completeness }\end{array}$ & $\begin{array}{l}\text { Unaware } \\
\text { Unable }\end{array}$ & $\begin{array}{l}\text { Unaware that family history can } \\
\text { sometimes play an important role in the } \\
\text { course of the disease. }\end{array}$ & 4 \\
\hline Family risk & $\begin{array}{l}\text { Technology: } \\
\text { information quality } \\
\text { - completeness }\end{array}$ & $\begin{array}{l}\text { Unaware } \\
\text { Unable }\end{array}$ & $\begin{array}{l}\text { Unaware that family risk can } \\
\text { sometimes play an important role in the } \\
\text { course of the disease. }\end{array}$ & 3 \\
\hline
\end{tabular}




$\begin{array}{lll}\begin{array}{l}\text { Patient's } \\ \text { preferences }\end{array} & \begin{array}{l}\text { Technology: } \\ \text { information quality } \\ \text { - compatibility }\end{array} & \begin{array}{l}\text { Aware } \\ \text { Unable }\end{array} \\ & & \\ \text { Imaging } & \begin{array}{l}\text { Human: system use } \\ \text { - knowledge }\end{array} & \begin{array}{l}\text { Aware } \\ \text { Able }\end{array} \\ & \begin{array}{l}\text { Technology: } \\ \text { information quality }\end{array} & \begin{array}{l}\text { Aware } \\ \text { Unable }\end{array} \\ \begin{array}{l}\text { Indication } \\ \text { for revision }\end{array} & \text { - compatibility } & \end{array}$

Treating physician

$\begin{array}{ll}\text { Indication } & \text { Human: system use } \\ \text { for } & \text { - knowledge } \\ \text { rediscussion } & \end{array}$

$\begin{array}{ll}\begin{array}{l}\text { Finalizing } \\ \text { the }\end{array} & \begin{array}{l}\text { Technology: service } \\ \text { quality } \\ \text { document }\end{array} \\ \text { - responsiveness } \\ \text { Attendees } & \begin{array}{l}\text { Technology: } \\ \text { information quality } \\ \text { - completeness }\end{array}\end{array}$

Searching Human: system use patients - knowledge

Aware

Unable

Aware Able

Aware Unable

Aware Able

Information standard languages

Terminology

Saving recorded information
Technology: quality - ease of use

Technology: information quality - compatibility

system

Aware

Unable

Unaware Able

Technology: service quality - responsiveness Able
Assumed that the preferences of the patients were unknown before the start of an MDT meeting. Believed consultations with the patient would be held afterwards in which the patient could indicate their preferences.

Able to insert a URL from the PACS software in the patient file.

This is considered preparation work before preparing the MDT meeting. This should be done in EPIC. This way, healthcare professionals can be notified of the required preparation before the MDT meeting.

This should be recorded in EPIC.

This can be realized by adding a patient to a new MDT meeting.

Can only be realized when NAVIFY is 3 fully integrated with EPIC.

Is added in the august/september 4 update.

A minimum of three numbers should be used when searching for a patient record number.

The software will be available in Dutch somewhere next year.

Unaware that this terminology could cause confusion. They will change these terms.

Unaware Unaware of this problem. Passed this information to the software developers.

Depending on how structured the walkthrough sessions were, the complete process for executing the comparative participatory cognitive walkthrough takes approximately 25 hours (see Table 2).

Table 2. Comparative participatory cognitive walkthrough phases and execution time

\begin{tabular}{lllllll}
\hline Phase & 1 & 2 & 3 & 4 & 5 & 6 \\
\hline Time & 5 hours & 1 hour & $5-10$ hours & 1.5 hours & $6-11$ hours & 1.5 hours \\
\hline
\end{tabular}




\section{Discussion}

In this study, an adaptation of a participatory cognitive walkthrough is proposed as a method to identify mismatches in cognitive models and potential usability issues new users of a system will encounter when switching to a new software programme or application.

With the comparative participatory cognitive walkthrough, holding two walkthrough sessions creates value. In an ordinary cognitive walkthrough (using only usability experts), a detailed analysis of potential problems results from the evaluation [18]. However, cognitive walkthroughs are tedious, discourage exploration and require detailed task description and user background details [18]. With our method, which involves both a medical specialist and a usability specialist, problems can be identified regarding terminology, lacking system functions or lack of data entry fields, the compatibility of the new software to the current work process, and how well the current steps can be executed using the new software (how many adaptations to the current work process are needed). For example, 'Family history' (status: unaware/unable) did not have a separate textbox. NAVIFY was unaware that, for some cancers, family history can contribute to a patient's treatment plan and should be recorded. This problem would not have been identified using an ordinary cognitive walkthrough without a medical specialist. As mentioned before, EPIC Care does not have a dedicated module for preparing MDTs, therefore, the identified tasks can be more tedious than necessary. However, our goal was to analyse the fit of two technologies and see which issues may occur when switching from one to another, not to evaluate the preparation process itself.

This quick (20-30 hours) evaluation method does not only benefit organizations looking for new software that matches the current work process well, but also for companies developing software. As mentioned before, there were aspects $(n=3)$ that NAVIFY did not consider relevant when the opposite is true. These can be implemented in the following update. Furthermore, since the Tumor Board is still under development, many of the identified aspects (status: aware/unable, $n=8$ ), were already being considered by NAVIFY. Finally, the aspects with a status aware/able $(n=3)$ are aspects that require more attention in training, since they are implemented, but in a different way than was expected by the 1 st and 3rd author.

The use of this method to identify mismatches in cognitive models when switching to different software or a different application should be explored further. In this study we explored the adaptation of this methodology with two participants. Therefore, results could be biased or only represent the views and experience for two particular individuals. This study can be repeated with multiple participants and more scenarios to fully comprehend the mismatches in the work processes and cognitive models, and in which domain these problems occur. With this knowledge, mismatches can be averted or prevented so the software will be more compatible with the current work process, which can ease the implementation and result in a higher acceptance.

\section{Conclusion}

The proposed comparative participatory $\mathrm{CW}$ provided useful insights in how well new software (NAVIFY Tumor Board) matches with the software currently in use (EPIC Care), by comparing the cognitive models in place when performing tasks involved with a specific scenario. The identified aspects can be of use for the development and 
adaptation of the new software, as well as provide guidelines on which aspects to focus on most when training healthcare professionals to use the new software in order to have a smooth transition of software.

\section{Acknowledgment}

\section{Martin van Middelkoop, implementation manager from Roche Diagnostics’ NAVIFY} Tumor Board.

\section{References}

[1] Volksgezondheidenzorg. Kanker $>$ Cijfers en Context $>$ Huidige situatie. Rijksoverheid Nederland. Accessed on 14-07-2021. Available from: https://www.volksgezondheidenzorg.info/onderwerp/kanker/cijfers-context/huidige-situatie\#!nodeaantal-nieuwe-gevallen-van-kanker

[2] Sottoriva A. Unravelling cancer's complexity. The Institute of Cancer Research. Accessed on 14-07-2021. Available from: https://www.icr.ac.uk/about-us/our-mission/our-research-strategy/unravelling-cancer-scomplexity

[3] Porter ME, Teisberg E. Redefining health care: creating value-based competition on results. Harvard Business School Press. 2006. ISBN 9781591397786.

[4] Nederlandse Kankerregistratie. Multidisciplinair overleg. Integraal kankercentrum Nederland. Accessed on 14-07-2021. Available from: https://iknl.nl/nkr/evaluatie-met-nkr-data/multidisciplinair-overleg

[5] Rajasekaran, R.B., Whitwell, D., Cosker, T.D., Gibbons, C.L., \& Carr, A. Will virtual multidisciplinary team meetings become the norm for musculoskeletal oncology care following the COVID-19 pandemic?experience from a tertiary sarcoma centre. BMC musculoskeletal disorders 2021; 22(1): 1-7.

[6] Interaction Design Foundation. How to conduct a Cognitive Walkthrough. Accessed on 14-07-2021. Available from: https://www.interaction-design.org/literature/article/how-to-conduct-a-cognitivewalkthrough

[7] Yusof M, Papazefeiropoulou A, Kuljis J, and Stergioulas L. An evaluation framework for Health Information Systems: Human, organization and technology-fit factors (HOT-fit). International Journal of Medical Informatics. July 2008; 77(6):308-98.

[8] Wallask S. Epic Systems. SearchHealthIT. Accessed on 14-07-2021. Available from: https://searchhealthit.techtarget.com/definition/Epic-Systems-Corp

[9] Epic. Software. Accessed on 14-07-2021. Available from: https://www.epic.com/software

[10] van Dorrestein M. AMC en VUmc kiezen definitief voor Epic. Accessed on 14-07-2021. Available from: https://www.zorgvisie.nl/amc-en-vumc-kiezen-definitief-voor-epic-1391186w/

[11] NAVIFY. About us. Roche. Accessed on 14-07-2021. Available from: https://www.navify.com/aboutus/

[12] Hammer RD, Fowler D, Sheets LR, Siadimas A, Guo C, and Prime MS. Digital Tumor Board Solutions Have Significant Impact on Case Preparation. JCO Clinical Cancer Information no. 4 (2020); 757-768.

[13] Hammer RD, Prime MS. A clinician's perspective in co-developing and co-implementing a digital tumor board solution. Health Informatics Journal (2020); Volume 26 issue 3: 2213-2221.

[14] Krupinski EA, Comas M, and Gallego LG. A new software platform to improve multidiciplinary tumor board workflows and user satisfaction: A pilot study. Journal of Pathology Informatics 2018; 9: 26.

[15] Fowler D, Sheets LR, Prime MS, and Siadmias A. The impact of a digital solution on case discussion time at tumor boards. Journal of Clinical Oncology. May 2019. 37(15 suppl):e18028-118028.

[16] Gardner C, Ghafur S, Fontana G, and Guo C. A mized methods study for the evaluation of a digital health solution for cancer multidisciplinary team meetings using simulation-based reserch methods. Journal of Clinical Oncology. May 2020.38(15_suppl):e14063-e14063.

[17] Nielsen J. Severity Ratings for Usability Problems. Nielsen Norman Group. Accessed on 18-7-2021. Available from: https://www.nngroup.com/articles/how-to-rate-the-severity-of-usability-problems/

[18] Jaspers MWM. A comparison of usability methods for testing interactive health technologies: Methodological aspects and empirical evidence. International Journal of Medical Informatics. 2009; 78: 340-353. 